\title{
Philosophizing in skilled nursing care: Must or nice?
}

\author{
Fatemeh Khoshnavay Fomani ${ }^{1}$, Mohammad Ali Cheraghi ${ }^{1}$, Yahya Ghaedi ${ }^{2}$, \\ Rahmatollah Kharazmi Rahimabadi ${ }^{3}$
}

\footnotetext{
${ }^{1}$ School of Nursing and Midwifery, Tehran University of Medical Sciences, Tehran, Iran

${ }^{2}$ Department of Educational philosophy, Kharazmi University, Tehran, Iran

${ }^{3}$ Department of Education, Farhangian University, Imam Ali (PBUH) Branch, Rasht, Iran

Email: f-khoshnava@razi.tums.ac.ir, cheraghiali2000@yahoo.com
}

Received 31 July 213; revised 5 September 2013; accepted 26 September 2013

Copyright (C) 2013 Fatemeh Khoshnavay Fomani et al. This is an open access article distributed under the Creative Commons Attribution License, which permits unrestricted use, distribution, and reproduction in any medium, provided the original work is properly cited.

\begin{abstract}
To become a professional nurse requires that nurses learn to think in a right way. Thinker nurses strive to be clear, accurate, logical, complete, precise and faire in their practice and manner. In other words, a thinker nurse is a philosopher who has the ability of reasoning, critical and reflective thinking. In many investigations, the role of critical or reflective thinking is explored, but in this review article, we are trying to introduce a comprehensive concept that involves all these elements of thinking skills. It is philosophizing.
\end{abstract}

Keywords: Philosophizing; Nursing Care; Thinking Skills

\section{INTRODUCTION}

"Nursing encompasses autonomous and collaborative care of individuals of all ages, families, groups and communities, sick or well and in all settings. Nursing includes the promotion of health, prevention of illness, and the care of ill, disabled and dying people. Advocacy, promotion of a safe environment, research, participation in shaping health policy and in patient and health systems management, and education are also key nursing role" [1]. If ever, there were a key component in nursing practice and education, it would be thinking [2,3]. For example, in clinical practice, the nurse engages in thinking and doing simultaneously [3]. Thinking is embedded in nursing care and quality of care is regarded as quality of thinking. Han (2007) stated that even in high technological care systems, we cannot disregard the role of thinking. Although in modern health care systems, much technological development has taken place in caring context, but quality of care is not depend on techno- logical developments solely. Albeit technology provides improvements in health care, but undoubtedly, effective use of thinking strategies is essential to provide a quailfied care [3].

\section{SKILLED NURSING AND REFLECTIVE THINKING}

Substantiation of care goals is based on knowledge and skills combined. In their qualitative study, Buller and Butterworth (2001) investigated the elements of skilled nursing and found that skilled nursing practice involves four domains: doing the job, being professional, relating \& communicating and managing \& facilitating [4]. Considering these four domains, it is evident that a skilled nurse is a thinker nurse because, the cornerstone of providing care, being a professional nurse, making relationship with patients and families or other members of profession and being a skilled manager, is thinking skills such as reflection or critical thinking. Shiau and Chen (2008) dissected reflection in medical care and enounced, while health professionals, are expressing care, they need to understand that "the process requires looking inward at one's own selves, then outward at the world around them, and then back in again" [5]. It means reflection. According John (1997) we use reflection on practice, in order to interpretation of process or experience. In Kember et al., (2000) definition, process of reflective practice, is a thoughtful practice into a potential learning situation. Hall (1995) introduced three types of reflection: reflection before action, reflection in action and reflection on action. Reflection as a mental process, applied to gain a better understanding of ideas that are relatively complicated [6]. By reflection, the nurse, can verify experiences or situations and analyze them. Also it is an opportunity to challenge values, beliefs and assumptions [5]. 


\section{SKILLED NURSING AND CRITICAL THINKING}

It is expected that a skilled nurse be adorned to reflective maturity because this competency is preliminary of humanistic care. Humanistic care is something more than medical care. It is a mainstream to get holistic care [5]. In our perspective, one way to get the competency of reflective maturity is critical thinking. According to Paull and Scriven (1987), critical thinking is process of analyzing, synthesizing and/or evaluating information. This is a worthy and fundamental concept in nursing curricula, practice and clinical decision-making because of its direct affects in patient outcomes. In context of nursing care, critical thinking is used to analyze patients situation, consider patients' circumstances, needs and feeling, assay nursing measures and recognize the appropriate time to seek alternative treatments. According to Staib (2003), critical thinker nurses, apply standards and seek information in their practice. They have logical reasoning skill and able to predict events or outcomes also they are capable to knowledge transformation [7,8]. Lewenson \& Truglio-Londriga (2008) acknowledged that health care arena is high complex and dynamic while many factors such as history, legal and ethical issues, spirituality, culture, media, economic status and health care policies, impress this circumstance [5]. It is clear that, in this battlefield, only a thinker nurse can overcomes the barriers and provides an eligible care.

\section{HOLISTIC CARE IN SKILLED NURSING AND THINKING}

In nursing discipline, the most preferred caring, is holistic care. This claim can be support by McEvoy \& Duffy (2008) explanation: "nursing is indeed holistic in nature" [9]. In the philosophy of holistic health care, people are something more than body and mind. Human is composed of mind, body and soul integrated into a whole with inseparable parts $[9,10]$. The whole is in dynamic interaction within itself and universe and well-being is the sequel of balance and harmony in all parts. Maybe Nightingale was the first nursing theorist that mentioned holistic care. When she (1996) stated one of the nurse's roles is putting the patient "in best condition for nature to act upon him", and for 100 years, the nursing, conform her guidance, the holistic health care in nursing practice, implicitly acknowledged. It is accepted that the nurse role is to help people get well, stay well and even have a peaceful death. It is Oppressive that, some nurses often failed to recognize the worthiness of their care [10]. Having a holistic point of view and doing this way, is embedded with thinking. Thinking process helps the nurse to understand the whole of clients or patients. Thinking is a magic wand for making harmonies or di- agnosing disharmonies and fixing that.

\section{HEALTH PROMOTION \& WELLNESS IN SKILLED NURSING AND THINKING}

Not only it is expected that nurses will be good thinker, but the community's expectations from nurses, is receiving services in the field of mind and thinking too. This expectancy is rooted in the nurses' roles in health promotion. For instance, mental health, as aspect of human health, is one of nurse's roles that is related to mind and thinking process. In the international classification of health workers (2010), nurses as "health workers", provide treatment, support and care services for people who are in need of nursing care due to the effects of ageing, injury, illness or other physical or mental impairment, or potential risks to health, according to the practice and standards of modern nursing" [11]. In this classification, providing care and treatment to individuals with mental problems is mentioned. Moreover health promotion and the desire to promote healthy communities is a focus in nursing discipline. These ideal goals are supported in nursing programs and curriculum as well as community activism by individuals and groups of nurses [12]. In other words, one of nursing mission is promoting wellness in individual and community levels. Moore \& $\mathrm{Hu}-$ erena (2005) and World Health Organization (2006) mentioned that the core of health concept is wellness. Carlson (2003) believes, wellness is based on promotion and maintenance of health and capacities for living rather than on healing of poor health and solving problems [13]. According to the Mickinley Health Centre, University of Illinois, wellness is "a state of optimal well-being that is oriented toward maximizing an individual's potential. This is a life-long process of moving towards enhancing physical, intellectual, emotional, social, spiritual and environmental well-being" [14]. When we talk about wellness promotion in nursing practice, we are confirming that a skilled nurse as a thinker health worker, is responsible to promoting all aspects of wellness in all levels of individuals, families and communities. Wellness, as mentioned above, is a process with a progressive essence to catch well being. How we can promote our wellness, without good thinking strategies? If we are nurse or patient, we must rely on our thinking skills to make our life better and get to our maximize potentials.

\section{PHILOSOPHIZING IN SKILLED NURSING}

For many years, we are training and educating our nursing students, to learn the way of right thinking. Not only in nursing education, but in any discipline, learning to be a good thinker, is focused and counts a worthy aim [15]. 
In modern academic educational systems, the ultimate goal is to produce individuals more than technicians who do any routine tasks in their profession or job. Graduates must possess creativity, imagination, sensitivity, and communication skills as well as proficiency and ability to analyze and synthesize situations. In medical education, goal oriented approaches, based on multidisciplinary integration, has the potential to prepare the individual to response to rapid changes in society and therefore, the professional members, will be more proficient in their roles and tasks [16]. Although many theorists try to find a feasible way to catch this educational systems desire, but historically, philosophy has been the ensign, in this battlefield. Between many models and methods trying to teach students, the right way of thinking, Matthew Lipman model (2003) was an innovative, walkaway and philosophical model that stand out. "Philosophy Goes to School" and the followed book titled "Philosophy in Classroom" as well as stories and exercise books for children and adolescents, was parts of Lipman effort in this way. He tried to explain how we can integrate philosophy examination to education [15]. In fact, Lipman as one of the most influential person in education introduced a new paradigm in this area and paved roads to reach their destination that has always been the desire of all actors in the field of education. His model adjusts to fast changing societies that are moving towards globalization and to the citizens who increasingly struggle to make sense of the world and of their lives [17]. This part of Lipman model, is exactly applicable to today's nursing world because of the changing nature of health care and globalization in nursing profession. Lipman believed that skilled individuals thinker, are those have three skills thinking: critical, creative and caring thinking [15]. Thus Lipman model can be an integrated framework that contains all core elements of thinking skills has been introduced in other models. There are some frameworks designed by theorists that introduced thinking skills, but the most widely accepted is Bloom's Taxonomy (1956) [18]. In lipman's model, creative and critical thinking is dealt with cognitive domain of Bloom's Taxonomy and caring thinking is mostly related to affective domain of this taxonomy. Caring thinking is just like a formula bringing critical and creative thinking together. Through caring thinking, we convert our felling to our choices, decisions and even judgments. Caring thinking is the philosophical verification and justification of critical and creative thinking [15]. Philosophizing is "to reason in the manner of a philosopher" [19]. Therefore according to lipman philosophical model, when we talk about philosophizing, in fact we are referring to critical, creative and caring thinking skills together. And a philosophizer, thus, who has the ability of analyzing, synthetizing, logical reasoning, predicting, thinking about our and other's ideas or emotions, verifying situations and challenging values and beliefs.

\section{CONCLUSION}

Philosophizing is a comprehensive concept that involves all elements of thinking skills. Nursing as a practical discipline, needs "practical nurses" and practical nurses are able to "practical think". It might seem that a practical thinker constantly eliminates thinking or reflection from the material world equation, but the material world and the world of thinking are and shall remain in an inseparable symbolic [20]. Especially in nursing care context, the nurse deals with a human as a patient or client. Going toward professionalism in nursing and providing holistic care for patients, or promoting health care and wellness in individual and society levels, it needs to apply good thinking strategies. Philosophizing is a cognitive competency that integrated all thinking skills and deserved to be included in education and nursing practice.

\section{REFERENCES}

[1] (2010) Definition of nursing. http://www.icn.ch/about-icn/icn-definition-of-nursing/

[2] Tanner, C.A. (2005) What have we learned about critical thinking in nursing? Editorial. Journal of Nursing Education, 44, 47-48.

[3] Han, K.J. (2007) Thinking in clinical nursing practice: A study of critical care nurses' thinking applying the thinkaloud, protocol analysis method. Asian Nursing Research, 1, 68-82. http://dx.doi.org/10.1016/S1976-1317(08)60010-9

[4] Buller, S. and Butterworth, T. (2001) Skilled nursing practice-A qualitative study of the elements of nursing. International Journal of Nursing Studies, 38, 405-417 http://dx.doi.org/10.1016/S0020-7489(00)00090-0

[5] Shiau, SH.-J. and Chen, CH.-H. (2008) Reflection and critical thinking of humanistic care in medical education. Kaohsiung Journal of Medical Sciences, 24, 367-372 http://dx.doi.org/10.1016/S1607-551X(08)70134-7

[6] Chelliah, K.K. and Arumugam, Z. (2012) Does reflective practice enhance clinical competency in medical imaging undergraduate? Procedia-Social and Behavioral Science, 60, 73-77.

[7] Naber, J. and Wyatt, T.H. (2013) The effect of reflective writing interventions on the critical thinking skills and disposition of baccalaureate nursing students. Nurse Education Today, 13, in press. http://www.nurseeducationtoday.com/article/S0260-6917 (13)00125-1/abstract

[8] Maneval, R.E., Filburn, M.J., Deringer, S.O. and Lum, G.D. (2011) Concept mapping: Does it Improve critical thinking ability in practical nursing students? Nursing Education Perspectives, 32, 229-233.

http://dx.doi.org/10.5480/1536-5026-32.4.229 
[9] McEvoy, L. and Duffy, A. (2008) Holistic practice-A concept analysis. Nurse Education in Practice, 8, 412419. http://dx.doi.org/10.1016/j.nepr.2008.02.002

[10] Erickson, H.L. (207) Philosophy and theory of holism. Nursing Clinics of North America, 42, 139-163. http://dx.doi.org/10.1016/j.cnur.2007.03.001

[11] World Health Organization (2010) Classification health workers. Geneva.

http://www.who.int/hrh/statistics/Health_workers_classifi cation.pdf

[12] Calloway, S. (2007) Mental health promotion: Is nursing dropping the ball? Journal of Professional Nursing, 23, 105-109. http://dx.doi.org/10.1016/j.profnurs.2006.07.005

[13] Rotegard, A.K., Moore, S.M., Fagermoen, M.S. and Ruland, C.M. (2010) Health assets: A concept analysis. International Journal of Nursing Studies, 47, 513-525.

[14] Mickinley Health Centre, University of Illinois at urbanchampaign. What is wellness? Understanding wellness. http://www.mckinley.illinois.edu/units/health_ed/wellnes $\underline{\text { s.htm }}$
[15] Dombayci, M.A., Demir, M., Tarhan, S. and Bacanli, H. (2011) Quadruple thinking: Caring thinking. Procedia Social and Behavioral Science, 12, 552-561. www.sciencedirect.com

[16] Watson, W.G. (1980) Philosophizing on educational goals. Editorial. American Journal of Orthodontics, 77, 227-229. http://dx.doi.org/10.1016/0002-9416(80)90008-1

[17] Lipman, M. (2011). Obituary. Thinking Skills and Creativity, 6, 143-145.

[18] Burke, L.A. and Williams, J.M. (2008) Developing young thinker: An intervention aimed to enhance children's thinking skills. Thinking Skills and Creativity, 3, 104-124. http://dx.doi.org/10.1016/j.tsc.2008.01.001

[19] An Encyclopedia Britannica company. Merriam Webster. Online dictionary. Philosophize. http://www.merriam-webster.com/dictionary/philosophiz $\underline{\mathrm{e}}$

[20] Gruioniu, O. (2013) The philosophy for children, an ideal tool to stimulate the thinking skills. Procedia-Social and Behavioral Sciences, 76, 378-382. 